\title{
NIGROMANCIA Y GÉNERO. LA BRUJA EN LA NARRATIVA DE PILAR PEDRAZA ${ }^{1}$
}

\author{
NECROMANCY AND GENDER/GENRE. \\ THE WITCH IN PILAR PEDRAZA'S FICTION
}

\author{
Miguel CARRERA GARRIDO \\ Universidad de Granada \\ mcarreragarrido@ugr.es
}

\begin{abstract}
Resumen: En su literatura —normalmente vinculada a lo fantástico y lo gótico-, Pilar Pedraza pone énfasis en individuos al margen, a menudo monstruosos. Entre todas estas figuras, destaca la de la bruja. El artículo estudia cómo la concibe la autora. A partir de las ideas expuestas en Brujas, sapos y aquelarres (2014) y el repaso de las obras más representativas, busca dirimir en qué medida el tratamiento de Pedraza afecta a su poética como creadora de una narrativa insólita y hasta qué punto se puede hablar de un enfoque específicamente femenino $\longrightarrow$ feminista - de este tipo de ficción, sobre todo en su vertiente gótica.
\end{abstract}

Palabras clave: Pilar Pedraza. Bruja. Narrativa fantástica. Narrativa de terror. Female Gothic.

Abstract: In her literature - commonly linked to the fantastic and the gothic -, Pilar Pedraza focuses on individuals on the margins, often monstrous. Among all these figures, the witch stands out. The article studies the way the author conceives it. Based on the ideas exposed in Brujas, sapos y aquelarres (2014) and the analysis of the most representative works, it aims to determine to what extent Pedraza's treatment affects her poetics as a producer of unusual fiction and to what extent we can consider it a specifically feminine - or feminist - approach to this type of fiction, especially on the gothic side.

Keywords: Pilar Pedraza. Witch. Fantastic fiction. Horror fiction. Female Gothic.

\footnotetext{
${ }^{1}$ El artículo es resultado de los proyectos de investigación Lo fantástico en la cultura española contemporánea (1955-2017): narrativa, teatro, cine, televisión, cómic y radio, del Ministerio de Economía, Industria y Competitividad (FFI2017-84402-P, I.P. Dr. David Roas), y Estrategias y figuraciones de lo insólito. Manifestaciones del monstruo en la narrativa en lengua española (de 1980 a la actualidad, del Ministerio de Ciencia, Innovación y Universidades (PGC2018-093648-B-I00, I.P. Dra. Natalia Álvarez Méndez).
} 
No dejarás vivir a la hechicera.

Éxodo, 22:17.

No quiero hablar mal de las mujeres. La mayoría de ellas son encantadoras. Pero es un hecho que todas las brujas son mujeres. No existen brujos.

Roald Dahl, Las brujas.

Las brujas son las personas que más tiempo llevan oprimidas sobre la tierra, pero esta, por fin, es la Estación de la Bruja. El mismísimo Satán se sienta en este comité, y demandamos el derecho de informarle y besarle el culo como hace toda América. Sharon Krebs, en un conjuro de W.I.T.C.H.

\section{INTRODUCCIÓN}

"Somos las nietas de las brujas que no pudisteis quemar". Tal fue una de las más coreadas consignas en las últimas manifestaciones del 8 de marzo, tanto en España como en otros países. El eslogan apunta a la inversión que se ha venido operando sobre una de las figuras más recurrentes del imaginario misógino y que, en la actualidad, atraviesa un momento álgido. Depositaria, como todo buen monstruo, de los miedos de la tribu - aquí, del patriarcado capitalista y judeocristiano-, su evolución corre pareja con la de otros engendros que, a lo largo de la historia, han encarnado, abierta o implícitamente, a la otredad temida y amenazante: los vampiros, los hombres lobo, las creaciones artificiales, los muertos vivientes. Todos han ido variando su significado en función de la mirada que se proyectase sobre ellos o del Zeitgeist correspondiente. En cuanto a la bruja, se impone, en la lucha por la igualdad, una gozosa apropiación de un significante tradicionalmente lastrado por connotaciones sexistas; proceso que lleva a ver a las brujas de las hogueras como "las primeras feministas" (Galanternik, 2019).

Ya propuesta por activistas radicales de la Segunda Ola — en concreto, por el grupo explícitamente bautizado W.I.T.C.H. (Women's International Terrorist Conspiracy from Hell), surgido a fines de los 60 en los Estados Unidos, al calor de las protestas contra la guerra de Vietnam y las movilizaciones de la izquierda más combativa (Wildburg, 2015)_, la reivindicación adquiere nuevo vigor en el presente milenio, tanto en el activismo como en la producción artístico-ficcional. Aun cuando en el lenguaje cotidiano bruja continúa siendo reconocido como un insulto dirigido en exclusiva a la mujer - emparentado con otros como zorra o perra $^{2}$-, las representaciones del arquetipo en los diversos discursos y expresiones artísticas marcan diferencias de peso con relación a los retratos acostumbrados en la literatura, el cine y la pintura de los siglos XIX y XX; y no me refiero solo a la dimensión más terrorífica u opuesta al buen gusto de la sociedad

\footnotetext{
${ }^{2}$ De acuerdo con la séptima y octava acepciones de la palabra en el $D L E$, una bruja sería, según el caso, una "[m]ujer de aspecto repulsivo" o directamente malvada; por no mencionar la quinta definición, relativa a los cuentos infantiles, que reúne ambos atributos (RAE y ASALE, 2014).
} 
biempensante — más monstruosa, en una palabra—, sino también a la, a priori, más amable y complaciente de ciertas comedias, o incluso de la ficción para niños y jóvenes. Como recuerda Creed (1993: 73), la bruja no siempre ha sido fuente de horror o ha hecho tambalearse el orden estatuido: también ha servido, paradójicamente, para reafirmar el patriarcado —en filmes y series como I Married a Witch (Clair, 1942) o Bewitched (Saks, 1964-1972) — o se ha erigido en estandarte del bien y la razón — caso de Glinda, la Bruja Buena del Sur en The Wonderful Wizard of Oz (1900), de L. Frank Baum.

Qué duda cabe, no obstante, de que son los valores oscuros, perturbadores, los que han predominado, al menos en los ámbitos del terror y lo fantástico. Conectada con el mito de la mujer rebelde (Gubern y Prat, 1979: 148-171) y las nociones de devoradora de hombres y castradora (Creed, 1993: 74), la bruja aglutina en su ser y sus acciones un rosario de rasgos contrarios al statu quo, esencialmente masculino y basado en principios como la unidad de la familia, la castidad femenina, la sumisión de la esposa al marido y la hija al padre, la idealización de la maternidad, etc. Como dice Abalia:

En respuesta al temor que ha suscitado la mujer, especialmente en períodos de incertidumbre, decadencia y represión, la creación artística ha oficiado como vehículo de expresión de dichos temores y deseos reprimidos, manifestados en forma de seres monstruosos y ambivalentes, que han protagonizado una parte importante de la iconografía femenina que conforma hoy nuestro imaginario de la feminidad (2013: 269).

Máxima encarnación del Otro hostil al horizonte patriarcal, la caracterización de la bruja, en especial desde los tratados áureos (Lara Alberola, 2012) — que fijan su imagen maléfica, muy distanciada de las hechiceras y encantadoras de la Antigüedad-, acumula atributos a cual más degradante: fealdad, crueldad, abyección, a los que debe sumarse una "capacidad de desencadenar fatalidades con su pensamiento, conjuros, vuelos mágicos, especialmente tendente al infanticidio, al canibalismo, a los cultos orgiásticos" (Abalia, 2013: 283). Esto es así porque, como resume Cortés, las brujas no solo simbolizan "lo horrible del ser humano, lo degradado, lo viejo, lo opuesto a la belleza y a la bondad"; también "la falsedad, el terror, el caos, lo que se desconoce y se teme, [...] el trasmundo oscuro y misterioso de lo pulsional e irracional" (1997: 47).

Contra tan negativa visión se levanta la autora que traigo a examen. Cultivadora de las vetas no miméticas o insólitas, su tratamiento del arquetipo nigromántico ${ }^{3}$ presenta trazas muy particulares. En diálogo abierto con las plasmaciones recién aludidas, da vida a personajes y episodios que, sin abandonar la dimensión perturbadora, la someten a manipulaciones que problematizan las bases del modelo en su versión tradicional. Dicho reajuste forma parte de un cuestionamiento global de la esencia misma de los géneros

\footnotetext{
${ }^{3}$ No voy a entrar aquí a establecer diferencias de peso entre las brujas o hechiceras de la Antigüedad y las de la Edad Media y la Edad Moderna, más allá de las que señalo a propósito de su lugar en la comunidad o su aura fantástica. Como hace la propia Pedraza en Brujas, sapos y aquelarres, las englobo a todas bajo un solo arquetipo, con la intención de homogeneizar el análisis; lo cual no quiere decir que no se puedan $-\mathrm{y}$ se deban - hacer precisiones nocionales y terminológicas. A este respecto, véase Lara Alberola (2010).
} 
fantástico y de terror - $\mathrm{o}$ gótico ${ }^{4}$ - , donde el factor monstruoso, en cualquiera de sus avatares, ocupa un lugar de privilegio y que, a primera vista, contrasta con la propuesta abordada. La inversión, a pesar de todo, no desemboca en un callejón sin salida, sino que, como se verá, da pie a un discurso trasgresor a la par que renovador.

\section{LAS BRUJAS PEDRACIANAS: ENTRE LO GÓTICO Y LA TRASGRESIÓN ¿FANTÁSTICA?}

No soy el primero en llamar la atención acerca de la centralidad de las brujas en la creación de la toledana Pilar Pedraza (1951). Ella misma no puede ser más elocuente en sus manifestaciones públicas y ensayísticas: aparte de la imagen cultivada en las redes sociales - en las que no es extraño verla invocando a Hécate o criticando con dureza a las instituciones tradicionales, en especial la Iglesia-, a su pluma se debe el interesantísimo ensayo Brujas, sapos y aquelarres (2014). Guiado por el mismo designio reivindicativo de La bella, enigma y pesadilla (1991), Máquinas de amar (1998) y Espectra, descenso a las criptas de la literatura y el cine (2004) - consistente en una relectura feminista de los seres, ficcionales y mitológicos, en los que se ha encarnado el miedo, a la par que el deseo, a la mujer-, en él se reúnen casi todas las claves para entender el concepto que la autora tiene del universo brujeril, así como para interpretar las narraciones que incluyen a hechiceras, magas y encantadoras en sus historias (Guillamón Carrasco, 2015). A sus páginas me remitiré para poner en relación el carácter de las brujas que protagonizan La fase del rubi (1987), Paisaje con reptiles (1996), Lobas de Tesalia (2015) o El amante germano (2018), entre otras, con el funcionamiento y los efectos de los géneros aludidos, según los conciben los especialistas. A tal fin se consagra la primera parte de este artículo.

No abundan los trabajos que recurran a principios teóricos específicos para definir la adscripción genérica de la obra de Pedraza ${ }^{5}$. Es común aludir a ella como la dama del gótico español (Vilar-Bou, 2016). Este título — cuestionado por la propia novelista ${ }^{6}$ lleva, empero, a más confusión que a otra cosa. Dejando a un lado la abusiva ampliación

\footnotetext{
${ }^{4}$ No es este el lugar para entrar en consideraciones terminológicas de calado. Aunque más adelante me refiero a las particularidades de cada categoría, convendría matizar los límites entre cada uno de estos géneros o modos (otra dicotomía que requeriría mayor reflexión). Para la oposición entre fantástico y gótico, remito a Aldana Reyes (2017: 9-13), y para un intento de diferenciación entre los tres, véase Carrera Garrido (2019: 525-529).

${ }^{5}$ Entre las aproximaciones de especialistas en lo fantástico y territorios más o menos vecinos, destacan las de Clúa Ginés (2006), Robles Moreno (2006), Pritchett (2015), Fernández Martínez (2015 y 2016) y Aldana Reyes (2017: 166-172). Tanto Clúa Ginés como Fernández Martínez conceden primacía al tratamiento del cuerpo y los nexos de la obra de Pedraza con la estética de la Nueva Carne. Robles, por su parte, relaciona su ficción con el gótico de los siglos XVIII y XIX, mientras que Pritchett y Aldana Reyes, desde un enfoque más abarcador, la asocian con el Female Gothic. A estas referencias cabe sumar la de Núñez Puente (2016), que vincula lo fantástico y la posmodernidad.

6 "No me importa que lo digan, pero creo que decirlo va un poco en detrimento de la literatura. Como decir 'ahí están los góticos, mira qué monos, jaja'. En su rinconcito. Y eso no es así. No debes dejar que te encasillen de esa manera tan cruel, porque es como una cuota” (Jonás y Ayuso, 2019).
} 
crítica del vocablo gótico (Levy, 1994), cualquiera familiarizado con la narrativa pedraciana convendrá en que no es el miedo — rasgo definitorio del género (Moers, 1976: 90; López Santos, 2008: 191; Punter, 2014: 13) - la razón de ser de esta. Los componentes macabros, perversos, extravagantes que la pueblan suscitan, antes que horror, incomodidad, cuando no curiosidad morbosa y decadente. Como concuerda Fernández Martínez, "su gótico no caus[a] miedo, sino que provo[ca] desasosiego e inquietud. La necrofilia, la escatología, la crueldad, la teratología o la frágil frontera entre la realidad apacible y la insólita realidad son algunos de sus temas predilectos" (2015: 178-179). Son pocos, por otra parte, los títulos de Pedraza que recurren a los cronotopos del gótico romántico; por no citar otros ingredientes distintivos — castillos, abadías, camposantos, criptas, damiselas en apuros, mefistofélicos villanos, tormentas y sentimientos desbordados - que, si aparecen, lo hacen con valores peculiares. Como sostiene la autora:

Yo gótica, gótica, no soy. No escribo a la manera de Mary Shelley y toda esa línea, lo mío es más de Bierce y de los contemporáneos. Aunque mis temas sean clásicos, los trato de otra manera. Hago reverdecer ciertos temas con una mirada contemporánea, pero desde luego no me considero una gótica (Jonás y Ayuso, 2019).

Dulce Gimeno, por su lado, apunta lo siguiente:

Pilar Pedraza es una autora atípica dentro del género gótico. El tratamiento que hace de los temas clásicos de la literatura de terror supera las reinterpretaciones para quedar asumidos en un universo particular y extraño, que sobrepasa los límites de unas historias de miedo para convertirse en algo más. En un reflejo de un mundo barroco y oscuro, plagado de tinieblas y obsesiones macabras, pero hermosamente retratadas (2009).

Es quizá por este particular tratamiento por lo que algunos han querido ver un parentesco no con la estela gótica en general, sino con una de sus variantes: el llamado Female Gothic. Este término, acuñado para referirse a la creación de seguidoras de la veta iniciada por Horace Walpole y The Castle of Otranto (Moers, 1976: 90-110), terminaría por aludir, con el paso del tiempo y el auge de la teoría literaria feminista - especialmente en sus indagaciones psicoanalíticas - a la recreación de la sensibilidad y la experiencia de la mujer en la narrativa de terror y a la posibilidad de formular una crítica de género - como la que se acomete, por ejemplo, en Williams (1995) o Wallace y Smith (eds., 2009)_. Por esta vía cobraría un poco más de convicción la afinidad entre Pedraza y el modelo gótico, ya no tanto por la índole terrorífica de su ficción cuanto porque, como dice Aldana Reyes, esta "shows a thorough engagement with the position of women in society and their desires, either rewriting Gothic myths or developing a modern Spanish version of them"7 (2017: 167). También es verdad, no obstante, que, mientras que el

\footnotetext{
${ }^{7}$ Para el cuestionamiento de esta categoría crítica, véase Ledoux (2017). Como dice la autora: "Narratives that focus on the struggles of a virtuous heroine often portray her as not only suffering, but also exerting agency, displaying physical courage, and gaining empowerment withing Gothic spaces" (2017: 3). No solo
} 
Female Gothic — por lo menos como es concebido por sus principales teóricos - concede primacía a la heroína atrapada y perseguida — evocando, de esta manera, los miedos femeninos-, pocas mujeres de este tipo vamos a encontrar en la narrativa de Pedraza. Así tendremos la ocasión de verlo con el ejemplo de las brujas.

Más incertezas despierta, en realidad, la identificación de la literatura pedraciana con el adjetivo fantástico: no en un sentido general(ista) — con el que ella, curiosamente, se siente más identificada (Vilar-Bou, 2016) y al que se acoge en sus reflexiones (Pedraza, 2008: 14)—, sino desde la restrictiva acepción de críticos como Roas (2011) o Caillois, que cifran el género en la violación escandalosa de las normas de la física y el discurso de lo real, y donde "lo sobrenatural aparece como una ruptura de la coherencia universal" (1970: 11). Situadas en contextos de lo más diversos y nutridas de elementos tomados de los ámbitos del arte, la religión y la mitología, las narraciones de Pedraza rara vez colocan en primer plano de importancia el cuestionamiento de los fundamentos de la realidad. De hecho, con frecuencia, la trasgresión de lo posible no genera apenas conflicto en los entes ficcionales — que pueden ser contemporáneos del lector, en todo similares a él一y se nos invita tácitamente a aceptar con pareja aquiescencia o despreocupación la irrupción de lo insólito e inconcebible, así como de lo que, en circunstancias normales, estimaríamos espantoso. Como explica Aldana Reyes: "Pedraza's use of horrific elements and monsters is [...] slightly different from that of other writers of more traditional horror [...]. [T]he supernatural can be both a source of fear and awe or fascination, even desire and love" (2017: 168). Semejante gama de respuestas provoca, como avanzaba, titubeos a la hora de precisar la naturaleza de la obra estudiada; también de juzgar el papel de los elementos puestos en juego. La bruja en sus diversos avatares sería uno de esos puntos sobre los que planea la duda: etiquetada, desde la sensibilidad y descreimiento contemporáneos, como ser fantástico y contrario a nuestra cosmovisión, su significado puede variar dependiendo del medio en el que se manifieste y la perspectiva desde la que se la enfoque.

"[T]he witch is essentially a being defined by supernatural power", sostiene Bosky (2006: 696) en la entrada correspondiente de Icons of Horror and the Supernatural; y en un pasaje anterior: "one of the defining characteristics of the witch is the capability of and inclination to do supernatural harm" (2006: 691). Ahora bien, si ese poder y ese daño que adornan a la nigromante prototípica conservan su vigencia en varios contextos, su trato con lo sobrenatural, en cambio, no siempre ostenta las mismas implicaciones ni genera el mismo impacto. Así lo evidencia la propuesta de Pedraza. Descreída confesa ${ }^{8}$, muchas de sus historias se remontan a periodos y sociedades cuyo sistema de creencias asume como normales las interferencias con lo que, a nuestros ojos, resulta extraordinario. La sorpresa,

eso: también hay personajes femeninos con perfiles mucho más siniestros, dudosamente virtuosos, en esta literatura. Como resume Ledoux, "women do not exclusively write about distressed virtue and the domestic sphere, and even when they do, the female characters represent a diversity of experience" (2017: 3).

${ }^{8}$ Así, en una entrevista dice: "soy agnóstica. No creo en el más allá ni en la vida después de la muerte en ninguna de sus variantes. [...] Mi predilección por estos temas es exclusivamente literaria, del mismo modo que lo es mi afición por la muerte" (Villalba, 2002), mientras que en otra va más allá: "Yo soy atea total" (Jonás y Ayuso, 2019). 
de esta forma, se ve neutralizada o, como poco, modulada. El aludido Aldana Reyes lo resume en los siguientes términos:

Belief in mythological creatures and their habitats is crucial, as the supernatural does not violate the real in her fiction, but bleeds into it. Since a number of Pedraza's novels are set in pasts where, either through personal or institutional religion, the beyond is not an extraordinary concept, magical elements blend into the narrative in ways that do not require a reconfiguration of human values or the characters' conception of the world (2017: 168).

Cabe enfatizar, en cualquier caso, la preferencia de la autora por el mundo pagano, anterior al cristianismo, donde, como advierte Pérez Ochando, "la adivinación, la vida de ultratumba y las intervenciones divinas se enhebraban en la vida" (2018: 83). Tan profunda era, en verdad, esta simbiosis, que lo irracional —incluida la hechiceríallegaba a formar parte de la organización legal de las ciudades, de la polis. Como dice Pedraza, estamos ante "una práctica sometida a las leyes civiles y a la religión, una divinidad protectora y una presencia aceptada como algo corriente en la sociedad en la vida cotidiana" (2014: 87). Que a menudo fuera prohibida por las autoridades, más que nada cuando se escoraba hacia las artes consideradas negras, no significa que se rechazase por quimérica, sino por peligrosa, esto es, por jugar con poderes que podían ser incontrolables y que, en la mayoría de los casos, contravenían la voluntad de los dioses del Olimpo. Es lo que sucede, por ejemplo, en El amante germano con Próxima Nigra, sentenciada a muerte por su magia, o en Lobas de Tesalia, con las brujas procedentes de dicha región. Estas, dice la narradora — también hechicera - "constituyen el oprobio de mi profesión [...]. Dotadas de terrible malignidad, son expertas en necromancia [...]. Las leyes de la ciudad las condenan a muerte por lapidación como al resto de los nigromantes" (Pedraza, 2015: 30).

Tampoco en este punto conviene hacer, sin embargo, afirmaciones rotundas, dado que, en los contextos descritos, las brujas no solo tenían un lugar en el tejido social, sino que podían gozar de un elevado estatus o contar con el respeto de la divinidad. Así ocurre con la aludida Próxima Nigra, de quien leemos:

Aquella mujer era un tesoro que había que preservar frente a la caterva de hechiceras incompetentes que infestaban Roma. Las brujas y herbolarias que hacían abortos y pelucas, y que de vez en cuando se prestaban a quitar de en medio a alguien con discreta habilidad en el mundo de los venenos, estaban bien para el populacho e incluso para plebeyos ricos. Pero había quienes querían y podían contar con alguien que no solo supiera de gemas o hierbajos, sino también de cómo llegar al corazón negro de Hécate o pedir favores especiales a Proserpina, la Terrible, y esa era la delicada y elegante Próxima, maga digna de moverse en la corte imperial (Pedraza, 2018: 181-182).

Investidas de predicamento social se presentan, también, Melanta, en La perra de Alejandría (2003) — más identificada, aun así, con el arquetipo de la mujer sabia, que con el de la nigromante- y Lupercia Mania, protagonista de Lobas de Tesalia. Esta última 
declara que, a diferencia de las practicantes de magia prohibida, ella "jamás había tenido el menor problema con las autoridades" y que se llevaba bien "con el sacerdote principal del templo de Esculapio, sobre todo después de haber hecho, bajo su égida, profesión de respeto a la medicina y veneración del dios de la vara y la serpiente" (Pedraza, 2015: 22). Así y todo, en cuanto descubre que su difunta amiga Póstuma ha mantenido contactos con las brujas tesalias y que, como ellas, ha participado en oscuros rituales, aun la percepción de aquellas se modula, pasando a verse todas como una comunidad bajo la protección de Hécate. Sus palabras son sintomáticas de la especificidad — ¿sororidad? — del colectivo: "Júpiter no era el Dios mayor de nuestro panteón común de mujeres, con la vista puesta más bien en Rea, diosa del transcurso del tiempo y de la menstruación, en Proserpina, reina de Hades, y sobre todo en Hécate, señora de las hechiceras" (Pedraza, 2015: 171).

Sobre Hécate, señala Pedraza "que no es el diablo"; nada más lejos de la realidad: "es una deidad del más alto rango, respetada por el propio Zeus, que cuenta con sus santuarios, templos y culto regular" (2014: 87-88). Dicha consideración da buena idea del grado de integración, incluso respetabilidad, del colectivo brujeril en la Antigüedad clásica. Habrían de pasar unos cuantos siglos y cambiar radicalmente el paradigma social y religioso para que la magia, como muchos otros elementos heredados de la Weltanschauung grecolatina, pasase a pertenecer al terreno de la superstición o, en los momentos más oscuros, a verse como encarnación del mal satánico; algo, en cualquiera de las acepciones, contrario a la cosmovisión judeocristiana y que, por ende, debía ser erradicado.

Este tránsito de un sistema creencial a otro, de una legislación a otra distinta, con la que entra en pugna, introduce necesariamente otra mirada en torno a lo que es admisible y lo que no, tanto en términos legales como físicos o metafísicos. Es el primer paso hacia la ficción fantástica como la entendemos hoy. Esta no se dará, con todo, hasta que hayan desaparecido todas las creencias y dogmas de tipo religioso, o bien estos hayan mutado - como decía Llopis en su primera redacción de la Historia natural de los cuentos de miedo (1974) ${ }^{9}$ - en una estética, o sea en recursos para generar emociones. En la obra de Pedraza —o más bien en su tratamiento del motivo brujeril — esto no se produce sino de una manera relativa. No quiero decir que se defienda la fe en una esfera trascendental, ni siquiera en la del mundo antiguo; solo que el juego entre realidades se relega, por lo general, a un plano secundario, y el miedo metafísico — "efecto esencial", según Roas (2011: 107), de lo fantástico - o bien no se da, o bien queda supeditado a otros aspectos de la narración, tangencialmente relacionados con la disrupción de lo real.

De registrarse una confrontación, esta atañe, me parece, a dos formas de entender la existencia, que involucran diferentes cosmologías y comprensiones de lo posible, pero cuya oposición va más allá: por un lado, la cristiana, en esencia patriarcal e intransigente, y, en el polo opuesto, la pagana, donde Pedraza aprecia mayor libertad y horizontalidad.

\footnotetext{
9 " [C]uando en la evolución progresiva de la conciencia humana muere una creencia, renace a un nivel superior en forma de estética. [...] Esto se puede aplicar, en líneas generales, a todo el arte. Pero en especial al cuento de terror" (Llopis, 1974: 19).
} 
En el mundo asociado a aquella, dice, "los seres humanos no estaban a expensas de los dioses, sino del destino, que no se podía cambiar. Los dioses podían ayudarte o ponerte las cosas difíciles, pero no dependías de ellos, como los cristianos dependen del suyo, patriarcal y tiránico" (Guillot, 2018). Es de la dialéctica existente entre estas dos concepciones — a la que podría añadirse, por la parte pagana, la libertina o sadiana - de donde dimana la trasgresión que simbolizan las brujas, y no tanto de la sobrenaturalidad de sus poderes o sus contactos con otras esferas de realidad. Como opina Pérez Ochando, se caracteriza la novelista por

insuflar vida a una visión del mundo en la que todavía tenían cabida lo sobrenatural y los prodigios. Lo que para nosotros es hoy fantástico pudo no serlo en el pasado; pero la mirada de la autora es siempre moderna y, en consecuencia, su uso de lo fantástico supone también una voluntad estética de trasgredir nuestra visión convencional del mundo y de romper $[\ldots]$ nuestras limitaciones cotidianas (2018: 83-84).

En efecto: al margen de que, aplicando estrictamente los cánones de la crítica, la obra de Pedraza podría llegar a verse, por la asunción de lo insólito como algo ordinario - es más, inscrito en un esquema de creencias y ritos organizado-, como maravillosa, antes que fantástica (Roas, 2011: 47), lo cierto es que prevalece el fin de oponer dos nociones de la existencia, tanto o más irreconciliables que las de lo posible e imposible; oposición que se articula tanto en el seno mismo de las obras como en el cotejo con la comprensión del mundo aún dominante en nuestro presente.

Enfocándonos en las brujas y en composiciones concretas, la colisión entre estos dos órdenes se hace obvia en el ajusticiamiento de Melanta. Aun cuando su figura - basada en Hipatia de Alejandría - caiga relativamente fuera del modelo brujeril, ejemplifica el planteamiento de Pedraza: su lapidación y descuartizamiento corren a cargo de una turba cristiana obsesionada con exterminar los modos de vida e instituciones de la Antigüedad, entre las que se encuentra la de la mujer sabia y conocedora de saberes trascendentes, que pasa a considerarse una amenaza. "Pintaremos las piedras de tu iglesia, Señor, con sangre de paganos", grita uno de sus ejecutores (Pedraza, 2009a: 174).

Como señala la autora, el Medioevo, que comienza respetando el legado clásico — también en materia de divinidades_- "poco a poco va problematizando la naturaleza y el poder de las brujas" (Pedraza, 2014: 88), modificando la percepción más o menos positiva - o al menos, indulgente - de antaño. Efectivamente, con la consolidación del paradigma judeocristiano, sobre las hechiceras va a ir pesando, cada vez con más fuerza, la sospecha, el rechazo. Es entonces, coinciden todas las voces, cuando se generaliza la asociación con Satán — que comparece, en expresión de Pedraza, "atendiendo más bien a las llamadas de la iglesia y de sus intereses que a los de la brujería” (2014: 18) — y la brujería se define como un peligro para la salvaguardia del alma y el mayor agente de la otredad femenina: la que comprende a la mujer en las facetas no sancionadas por el orden patriarcal, aquella que se opone, ya no tanto al compendio de creencias como al de valores sociales, políticos y éticos del modelo dominante. En referencia a esto, dice Cortés que 
"[m]uchas de las imágenes de la mujer castradora se recrean en una visión [...] como antimadre, madre asesina o deseosa de la carne y la sangre del hombre" (1997: 47; cursiva del autor), en tanto que Gubern y Prat se hacen eco, en su examen de la mujer rebelde, de "la destrucción familiar, protagonizada por la mujer insumisa y consecuencia de su erotismo desbordado" (1979: 164).

Así las cosas, si la obra de Pedraza acude una y otra vez al motivo de la bruja, no lo hace en aras de un discurso que favorezca el consabido efecto fantástico por encima de cualquier otro objetivo. Desde luego que quiere desestabilizar al lector; ahora, más que revelarle lo que se oculta tras los límites de lo real - parafraseando a Roas-, su principal interés pasa por confrontarlo con realidades culturales marginadas, estigmatizadas, cuya visibilización pone en jaque las convicciones de Occidente, en una línea muy similar a lo que Rosie Jackson, en Fantasy: literatura y subversión (1986), atribuía a lo fantástico desde su abarcadora concepción. Como decía, este género

es una literatura subversiva. Existe al costado de "lo real", a ambos lados del axis cultural dominante, como una presencia enmudecida, un otro imaginario silenciado. Estructural y semánticamente, lo fantástico se dirige a la disolución de un orden que se experimenta como opresivo e insuficiente (1986: 188).

Es una visión que resuena en las palabras de la propia Pedraza, en Vigencia de lo fantástico en el imaginario moderno; como allí dice: "esta forma de creación se las arregla para disolver la censura institucional y familiar, dejándonos libre un camino por el que transitar por los territorios de la transgresión so capa de libertades de la imaginación" (2008: 46). Se trata de una postura que, por lo demás, ya ha sido recogida por la crítica feminista de las modalidades de lo insólito; rechazando la existencia del llamado fantástico femenino (Richter, 2011), con su esencialismo y lugares comunes en torno a la condición de la mujer, prefiere, en cambio, hablar de un enfoque feminista, reivindicativo, del género. Así se constata, entre otros testimonios, en el prólogo a Insólitas. Narradoras de lo fantástico en Latinoamérica y España, donde leemos que

lo insólito desenmascara la naturaleza relativa y arbitraria del sistema social, se opone al orden institucional y expresa los impulsos que deberían ser reprimidos desde la perspectiva de lo normativo, por lo que puede resultar lógico que las mujeres, como identidades que no han gozado del privilegio, encuentren un espacio de libertad en la narrativa no realista y su capacidad para reflejar las tensiones entre la ideología y el sujeto humano (López-Pellisa y Ruiz Garzón, 2019: XIX).

Cosa que se da también, ciertamente, en Pedraza. Según Palmieri: "La narrativa de la autora manifiesta una premura constante en buscar imágenes femeninas que puedan desmentir el papel que tienen en el orden literario, abarcando así nuevos horizontes" (2017: 162). Son, así, el protagonismo, el poderío y la independencia que cobran en sus ficciones los seres al margen - monstruosos en el sentido amplio de la palabra; femeninos, muchos de ellos (Galego Gen, 2009) — lo que desequilibra las certezas del 
receptor, y no sus acciones contrarias a las leyes de la física. La figuración de aquellas suele distinguirse, por lo demás, por un acentuado - y pretendido - anticlímax, aun en las historias más próximas a la sensibilidad moderna. Véase, si no, el caso de La fase del rubi, cuyos protagonistas masculinos -irónicamente dos funcionarios de la Inquisición - no solo desdeñan como supercherías hechos que los lectores sabemos de origen sobrenatural, en conflicto con las expectativas de su época —el siglo XVIII, nada menos-, sino que también frivolizan sobre la quema de brujas (Pedraza, 2009b: 62). En esta novela tenemos, por otro lado, la celebración de un aquelarre, descrito con harta displicencia, sin épica alguna, por la narradora:

Se ponen [las brujas] frente al trono y relatan pecados miserables con voces incultas. Son historias pesadas y ridículas, carentes de interés, que siempre parecen la misma. Tengo que reprimir un bostezo. [...] Cuando acaba la ceremonia de la confesión y todos se ponen en fila para saludar al señor Leonardo besándole en el ano y los oscuros testículos, me aparto un poco y me siento en un tronco caído. Estas tonterías me ponen de mal humor (Pedraza, 2009b: 198-199).

Tal sensación de cotidianidad, de aceptación no conflictiva se repite, hasta cierto punto, en Paisaje con reptiles, ubicada en una isla tropical donde el vudú y otras prácticas de magia negra sobreviven y son percibidas por los lugareños $-\mathrm{y}$, a la postre, también por la española Alicia - como parte de su día a día. "No iba a ser fácil seguir su consejo de alejarme de aquello", dice la protagonista (Pedraza, 1996: 118) en alusión a los prodigios que se multiplican a su alrededor. "Empezaba a parecerme natural; allí lo era".

En ambas narraciones, lo que se dispone en primer lugar de relevancia, lo que se enfatiza, no son, como digo, los atentados contra la idea de lo posible, sino lo que subyace, en un sentido cultural e ideológico, a estas cosmovisiones, a esas otras formas de entender la sociedad y a los seres humanos - las mujeres, en particular-, de las que las brujas serían un portavoz privilegiado. El diálogo que la obra pedraciana entabla con la representación de estas en el imaginario occidental —en especial con sus avatares literarios y fílmicos - me lleva de vuelta al comienzo del artículo y nos permite observar con claridad el sentido último de su trasgresión, así como las razones por las que, cuestionado el vínculo con lo fantástico estricto, podría justificarse la afinidad con el Female Gothic... si bien en los términos de empoderamiento y afirmación antes avanzados.

\section{LAS BRUJAS DE PEDRAZA Y LA SUBVERSIÓN DE LOS VALORES PATRIARCALES}

De acuerdo con la citada Bosky, la imagen que tiende a venirnos a la cabeza cuando pensamos en una bruja, es la de "a woman, old and baleful, perhaps with a long, warty nose and one clouded eye", la cual se reúne en conventículos con otras como ella para, en connivencia con el Diablo, practicar magia; una magia que, dice la estudiosa, "is 
always harmful, usually involving herbs, recited spells, or a doll that symbolizes her victim" (2006: 689). Se trata, sin duda, de la visión más extendida en la cultura popular, que, como decía, es fácil constatar en los cuentos infantiles y las películas más convencionales de terror, así como en un generoso número de relatos, novelas y obras de teatro, donde las hechiceras son el enemigo, el repelente y dañino monstruo al que se enfrentan los héroes - representantes del bien-y que solo a veces son capaces de derrotar (Creed, 1993: 2). Algunos ejemplos de tal concepción serían "The Dreams in the Witch House" (1933), de H. P. Lovecraft, The Witches (1983), de Roald Dahl, Weaveworld (1987), de Clive Barker, La dama número trece (2003), de José Carlos Somoza, o Hex (2013/2016), de Thomas Olde Heuvelt; y en la pantalla, amén de las adaptaciones de las narraciones de Lovecraft, Somoza y Dahl - y la que está en marcha, por lo visto, de Olde Heuvelt—, La maschera del demonio (Bava, 1960), Night of the Eagle (Hayers, 1962), The Blair Witch Project (Myrick y Sánchez, 1999) o Antichrist (Trier, 2009).

En la mayor parte de estos productos, la figura brujeril remite a la interpretación de Jung, para quien aquella supondría "una proyección del ánima masculina, es decir del aspecto femenino primitivo que subsiste en lo inconsciente del hombre; [...] esta sombra rencorosa, de la que ellos no pueden apenas liberarse, y se invisten al mismo tiempo de una potencia temible" (Chevalier, 1986: 200). Se trata, sin titubeos, de la concepción más negativa, forjada desde la mirada masculina —o, mejor dicho, desde el más rancio prisma misógino-patriarcal - y que Creed, en su análisis de la versión cinematográfica de Carrie (De Palma, 1976), desgrana combinando conceptos del psicoanálisis clásico con la terminología de Julia Kristeva:

The witch is defined as an abject figure in that she is represented within patriarchal discourses as an implacable enemy of the symbolic order. She is thought to be dangerous and wily, capable of drawing on her evil powers to wreak destruction on the community. The witch sets out to unsettle boundaries between the rational and irrational, symbolic and imaginary. Her evil powers are seen as part of her "feminine" nature (Creed, 1993: 76).

En pugna con tan oscura percepción están obras como las de Pedraza, que apuestan por concederle a la mujer figuraciones y atributos más dignos y, sobre todo, contundentes de los que, tradicionalmente, ha recibido en el discurso ficcional, en especial en el terror y lo fantástico. Ello, que se podría pregonar a propósito del personaje heredado del gótico clásico de la heroína en apuros, se aplica, en este caso, a las representaciones monstruosas del sujeto femenino, en particular a la figura de la bruja.

"Aunque el cine de terror suele jugar a transgredir las normas, tiende a reproducir un punto de vista", se quejaba Franch (2016) en su reseña de Blair Witch (Wingard, 2016); "las brujas son seres malignos a los que erradicar, y raramente se representan como seres perseguidos". El razonamiento, que podría haber tenido alguna base en la centuria pasada o aun a principios de esta, posee hoy mucho menos fundamento, tanto con relación al cine 
como a otras artes: a poco que uno se pare a mirar, observará que lleva años en marcha una inversión — $\mathrm{o}$, cuando menos, resignificación - de los rasgos y los valores comúnmente asociados al personaje de la bruja. Tal vez esta relectura no vaya, sin embargo, por donde desearía el crítico, o sea por la mostración de sus cuitas y la empatía con su padecimiento. Lejos de esta actitud conmiserativa - tanto como de la que hacía de la bruja una ama de casa complaciente o una suerte de hada madrina-, son cada vez más los autores — hombres y mujeres — que prefieren mostrar a personajes fuertes, libres de toda atadura ideológica, cuyos actos no tienen por qué coincidir con la moral de la época — ni de la nuestra ni de la figurada -; que hasta pueden llegar a antojársenos villanos, pero que, al final, se afirman frente a un sistema opresivo. Las muestras son abundantes en el cine y la televisión más recientes: desde la celebrada The Witch (Eggers, 2015) hasta el remake de Guadagnino (2018) de la ya potente Suspiria (Argento, 1977), así como otras producciones menos sonadas: The Autopsy of Jane Doe (Øvredal, 2016), The Love Witch (Biller, 2016) o la serie juvenil Chilling Adventures of Sabrina (AguirreSacasa, 2018-2020). En cuanto a la literatura, los ejemplos se remontan hasta títulos como Macmep u Mapzapuma (1966), de Mijaíl Bulgákov, The Witches of Eastwick (1984), de John Updike o The Mists of Avalon (1983), de Marion Zimmer Bradley — versión del mito artúrico narrada por la hechicera Morgana-, para alcanzar en proyectos como el de Pedraza una culminación gloriosa.

Repasando los relatos de nuestra autora que incorporan figuras brujeriles, llama la atención que, en verdad, muy pocas presentan un perfil heroico, modélico o luminoso. Algunas, como Imperatrice en La fase del rubí, Ericta y Póstuma en Lobas de Tesalia, o las Toussaint en Paisaje con reptiles, poseen un perfil francamente siniestro, mas no por su apariencia — que, en el caso de la primera, no puede ser más agraciada ${ }^{10}$ —, sino por sus horrendas acciones y su innegable crueldad. Lo mismo se puede aplicar a Antida Colás, también de La fase del rubí, y a la niña Ángela, nombre irónico donde los haya: personaje secundario de la nouvelle Las novias inmóviles (1994) y (anti)heroína del cuento "Mater Tenebrarum" (2000), su parentesco con la picaresca y la empatía del narrador no invalidan su nexo con las madres imaginadas por De Quincey en Suspiria de profundis (1845) y protagonistas de la trilogía de Dario Argento ${ }^{11}$. Al contrario de las otras brujas citadas — a excepción de Antida - Ángela es un ser marginal, que vive en la miseria y cuya formación corre a cargo de la vieja Crisanta, hechicera clandestina, degenerada y rencorosa:

\footnotetext{
${ }^{10}$ Imperatrice también ha sido relacionada con el arquetipo vampírico, como una pariente cercana de la Clarimonda de "La norte amoureuse" de Théophile Gautier (Galego Gen, 2009: 151) o, especialmente, del personaje histórico Erzsébet Báthory, la Condesa Sangrienta, de quien "podría ser muy bien la compañera de juegos" (Suárez Briones, 2002: 337).

${ }^{11}$ Conocida como Las tres madres, la trilogía se compone de los filmes Suspiria (1977), Inferno (1980) y La terza madre (2007). A ella le dedica Pedraza generosa atención en su libro Brujas, sapos y aquelarres, (Pedraza, 2014: 276-280). Entre las últimas publicaciones de la autora figura, además, toda una monografía dedicada al asunto (Pedraza, 2020).
} 
Había conocido tiempos mejores, pero de tanto empinar el codo perdió muchos de los dones que había recibido de su estirpe de hembras que, de madres a hijas, habían ido pasándose el pacto con Satanás y ratificándolo con una gota de sangre. Si parecía una mendiga, no era por pobreza, sino por la peor de las miserias: la avaricia, que la tenía reconcomida, muerta de hambre y hecha un puro andrajo, aunque se sentara sobre los tesoros que escondía en su nido de urraca (Pedraza, 2009c: 958-959).

Siendo todo esto así, uno se preguntaría, muy legítimamente, qué distingue a estas visiones de Pedraza de las que venimos criticando, fruto de la óptica patriarcal; si no sería mejor, después de todo, erigir criaturas bondadosas e injustamente perseguidas; dotadas, a la vez, de unos principios éticos y sociales con los que nos pudiéramos identificar con mayor facilidad y convicción. La respuesta es, huelga aclararlo, no. Si de algo huye la autora, es, precisamente, de la comodidad y la complacencia; acogerse a estas equivaldría a contravenir el primer designio de su ficción — además de reproducir tópicos tanto o más machistas - esa dialéctica o trasgresión que, decíamos, vertebra sus creaciones. Como dice Fernández Martínez: "Pilar Pedraza utiliza el género gótico para crear personajes transgresores y subversivos con una doble intención: por un lado, (des)marcar lo excéntrico y, por otro, vislumbrar la relación marginal con la sociedad hegemónica" (2016: 116). En su escritura, apunta Palmieri, las monstruas "nacen en el imaginario de una perspectiva femenina, o sea, están creadas por una autoría que encuentra difícil seguir el camino literario hasta ahora propuesto por los hombres" (2017: 183). Ahí es, a todas luces, donde estriba la diferencia, la particularidad respecto a otras concepciones en apariencia más positivas de la bruja (incluida la sugerida por Franch); porque, como sigue Palmieri:

Si desde siempre las protagonistas de la novela fantástica se han presentado como víctimas de situaciones manifiestamente injustas, sujetas a los abusos de villanos y anhelantes de la ayuda de un héroe, en las novelas de Pedraza el foco narrativo se centra totalmente en ellas; les permite ser las villanas o las heroínas de sus propias historias, construyendo en cierto modo una literatura de denuncia y paradoja a la vez (2017: 183).

No se trata, entonces, de plantear un discurso diáfano ni unidimensional, ni operar una inversión simple, que convierta a las brujas de antaño en dechados de virtud o almas injustamente oprimidas, en torno a las cuales orbiten los miedos de la mujer: al fin y al cabo, la ficción de esta clase está repleta de mujeres en el papel de víctima. Aprovechando los mecanismos del género terrorífico, en los que la monstruosidad y el mal desempeñan papeles decisivos, las historias de Pedraza nos ponen frente a hechiceras que, pese a conservar gran parte de los rasgos tradicionalmente asociados con el arquetipo, consiguen trascender, merced a su autonomía, su fuerza y capacidad de decisión, la misógina imagen patriarcal; expresado de otro modo: que, siendo y comportándose como sujetos provistos de agencia, escapan, al mismo tiempo, a la visión dulcificada o victimizada de su monstruosidad y a aquella que las reducía a meros receptáculos de los miedos del hombre. 
"[S]i Pedraza quiere reivindicar en su ficción a las mujeres malas, de nuevo lo consigue", dice Robles Moreno (2006: 270; cursiva de la autora) en referencia a Melanta. Claro que el adjetivo es, en buena medida, irónico: estas mujeres malas constituyen la airada respuesta de la narradora a la hegemónica óptica falocéntrica, que ha subestimado durante centurias a la mujer, insistiendo en su debilidad o tornándola, cuando más, una deleznable esclava de Satán. La nueva posición de fortaleza la sintetiza a la perfección la protagonista de La pequeña pasión (1990) — que, pese a no ser bruja, también se reconoce sierva de Hécate - hablando sobre la relación con su pareja:

Él nunca ha sabido lo que temía; yo, sí: mi feminidad. Supongo que soy una devoradora, como todas las hembras, aunque procuro moverme en el mundo con la mayor discreción posible. [...] Muchos me han tenido miedo [...]; miedo a defraudarme, a no estar a mi altura y a que les castigara por ello de una manera que no puedo ni imaginar. Mater Tenebrarum (Pedraza, 1990: 65).

Perversas y retorcidas, fieramente hostiles a las convenciones de su tiempo, si algo está claro es que las brujas pedracianas no sirven a dueño alguno - menos que ninguno, al Diablo del cristianismo-, hacen lo que quieren, tanto con su cuerpo como con lo demás, $\mathrm{y}$, si son condenadas por sus fechorías, o bien logran escapar a última hora, como Próxima Nigra, o mueren afirmando su personalidad y atrocidades, como Melanta —que, de hecho, vuelve del más allá para continuar con ellas - o como la narradora de La fase del rubí. De ellas dice Palmieri que "se caracterizan por una sexualidad y un estilo de vida totalmente independiente o, mejor dicho, emancipado. Aunque los demás intentan reprimir estas inclinaciones animalescas, al final ellas resultan ganadoras" (2017: 176). A ello se suma el hecho, nada baladí en este terreno, de que por lo menos Imperatrice, entre otras maléficas del repertorio pedraciano - también Lupercia Mania-, es "la dueña absoluta de su propia historia" (Fernández Martínez, 2016: 108), cuenta con el poder de la palabra que, durante siglos, le ha sido negado al monstruo en la ficción (Campra, 2008: 139-165) y a la mujer en la sociedad. El ejercicio mismo de la narración rompe las cadenas de este secular cautiverio... manteniendo, eso sí, su condición monstruosa ${ }^{12}$.

"Liberarse de ¿qué monstruosidad?", pregunta, sintomáticamente, Pedraza, y responde: "Liberarse del mundo patriarcal. Ser libre, diría yo, porque la expresión libre es libertad. [...] Sé que vivimos en una sociedad patriarcal y lo denuncio siempre que puedo, pero no quiero mujeres victimistas, sino mujeres libres e iguales" (Palmieri, 2017: 282). En dicho espíritu de denuncia descansa la creación de personajes fuertes, a contrapelo de las asunciones del lector más conservador, quienes, con sus aventuras y desventuras, con sus opiniones y su conducta, hagan estallar los estereotipos y fuercen una relectura del imaginario occidental; relectura que, urge precisar, en ningún caso ha de conducir a la confrontación entre los seres humanos, ni siquiera de mujeres contra hombres, sino al levantamiento contra un sistema que, a la postre, nos oprime a todos;

\footnotetext{
${ }^{12}$ Al contrario, pues, de lo que pasaría, según Roas (2019), con muchos monstruos en la posmodernidad.
} 
que, bien considerado, va más allá del patriarcado, proyectándose hacia la mecanización de la vida, la banalización de los afectos y la destrucción del planeta (Pedraza, 2014: 258). De ahí el concepto de feminismo socialista defendido por Pedraza, pactado con el varón y crítico con una visión victimista de la mujer. He aquí el verdadero sentido de su escritura y el tamaño de su trasgresión; tal es, en fin, el objetivo al que obedece la reformulación de la bruja, bajo una óptica que, a medio camino entre el terror, lo fantástico y el Female Gothic, quizá sea mejor llamar, simplemente, pedraciana.

\section{REFERENCIAS BIBLIOGRÁFICAS}

Abalia, A. (2013). Lo siniestro femenino en la creación plástica contemporánea. Análisis y experimentación. Bilbao: Universidad del País Vasco.

Aldana Reyes, X. (2017). Spanish Gothic. National Identity, Collaboration and Cultural Adaptation. London: Palgrave Macmillan.

Bosky, B. L. (2006). "The Witch". En Icons of Horror and the Supernatural: An Encyclopedia of Our Worst Nightmares, S. T. Joshi (ed.), 689-722. Westport, CT / London: Greenwood Press.

Caillois, R. (1970 [1966]). Imágenes, imágenes, D. Sierra y N. Sánchez (trads.). Barcelona: Edhasa.

CAMPRA, R. (2008). Territorios de la ficción. Lo fantástico. Sevilla: Renacimiento.

CARrera GARrido, M. (2019). “'Do you wanna play a game?'. Espacio y niveles de implicación del público en la representación escénica del género terrorífico". Signa. Revista de la Asociación Española de Semiótica 28, 523-560. Disponible en línea: http://revistas.uned.es/index.php/signa/article/view/25069/19908 [19/02/2021].

Chevalier, J. (1986 [1969]). Diccionario de los símbolos, M. Silvar y A. Rodríguez (trads.). Barcelona: Herder.

CLÚA GINÉS, I. (2006). "De la carne como una de las bellas artes: cuerpo, artificialidad y tradición fantástica en la obra de Pilar Pedraza". En Actas del II Congreso de la Sociedad Española de Estudios de Cultura Popular (SELICUP). Literatura y cultura popular en el nuevo milenio, M. Cousillas y J. Á. Fernández Roca (eds.), 321-335. A Coruña: SELICUP / Universidade da Coruña.

CORTÉS, J. M. G. (1997). Orden y caos. Un estudio cultural sobre lo monstruoso en el arte. Barcelona: Anagrama.

Creed, B. (1993). The Monstrous Feminine. Film, Feminism, Psychoanalysis. London / New York: Routledge.

Dulce Gimeno, J. (2009). "La Dama Negra. Entrevista con Pilar Pedraza". Ábrete Libro. Revista Digital sobre Libros y Autores, noviembre. Disponible en línea: http://revista.abretelibro.com/2009/11/pasion-por-lo-macabro-literaturade_08.html [03/11/2020]. 
FERNÁNDEZ MARTíneZ, S. (2015). "La Nueva Carne: Génesis y corpo/realidad femenina en la narrativa de Pilar Pedraza". En Espejismos de la realidad. Percepciones de lo insólito en la narrativa española (siglos XIX-XXI), N. Álvarez Méndez y A. Abello Verano (eds.), 179-188. León: Universidad de León.

(2016). "Carne subversiva. La perversión como écfrasis en La fase del rubí, de Pilar Pedraza”. En Territorios de la imaginación. Poéticas ficcionales de lo insólito en España y México, N. Álvarez Méndez, A. Abello Verano y S. Fernández Martínez (eds.), 105-120. León: Universidad de León.

FRANCH, I. (2016). "Brujas malvadas, brujas enamoradas, brujas empoderadas". Eldiario.es, 4 de noviembre. Disponible en línea: https://www.eldiario.es/cultura/cine/Brujas-malvadas-brujas-enamoradasempoderadas_0_576742618.html[03/11/2020].

GALANTERNiK, V. (2019). "Por qué las brujas fueron las primeras feministas y cómo revive hoy su historia". La Nación, 12 de febrero. Disponible en línea: https://www.lanacion.com.ar/lifestyle/por-que-brujas-fueron-primerasfeministas-como-nid2217082 [03/11/2020].

Galego Gen, A. M. (2009). "Lo monstruoso en la narrativa de Pilar Pedraza”. En Héroes, mitos y monstruos en la literatura española contemporánea, F. López Criado (coord.), 149-156. Santiago de Compostela: Andavira.

Gubern, R. y PRAt, J. (1979). Las raíces del miedo. Antropología del cine de terror. Barcelona: Tusquets.

Guillamón CARrasco, S. (2015). "Brujas, sapos y aquelarres, Pilar Pedraza”. Eutopías. Revista de Interculturalidad, Comunicación y Estudios Europeos 9, 169171. Disponible en línea: https://ojs.uv.es/index.php/eutopias/article/view/18756/ $16347[17 / 02 / 2021]$

Guillot, E. (2018). "Pilar Pedraza: 'Me divierte tanto la información científica como la ficción"”. Culturplaza, 20 de abril. Disponible en línea: https://valenciaplaza.com/pilar-pedraza-me-divierte-tanto-la-informacioncientifica-como-la-ficcion [03/11/2020].

JACKSON, R. (1986 [1981]). Fantasy: literatura y subversión. Buenos Aires: Catálogos Editora.

JonÁs, R. Y AYUSO, B. (2019). "Pilar Pedraza: 'Que no me digan que no debo leer a Sade por ser patriarcal, porque los mando a la mierda"'. Jot Down. Contemporary Cultural Mag, 11 de noviembre. Disponible en línea: https://www.jotdown.es/2019/11/pilar-pedraza-que-no-me-digan-que-no-puedoleer-a-sade-porque-es-patriarcal-porque-los-mando-a-la-mierda/ [03/11/2020].

Lara Alberola, E. (2010). "Por qué y para qué: función de las hechiceras y brujas en la literatura de los Siglos de Oro". Espéculo. Revista de Estudios Literarios 44. Disponible en línea: http://webs.ucm.es/info/especulo/numero44/hechibru.html [17/02/2021]. 
(2012). "El terror de la brujería: antecedentes de un motivo literario gótico". Polifonia 2.1, 68-87. Disponible en línea: https://www.apsu.edu/polifonial volume2/e5.pdf $[03 / 11 / 2020]$.

Ledoux, E. (2017). “Was There Ever a 'Female Gothic'?”. Palgrave Communications 3, s. p. Disponible en línea: https://doi.org/10.1057/palcomms.2017.42 [17/02/2021].

LEVY, M. (1994). "'Gothic' and the Critical Idiom”. En Gothick Origins and Innovations,

A. Lloyd-Smith y V. Sage (eds.), 1-15. Amsterdam: Rodopi Press.

Llopis, R. (1974). Esbozo de una historia natural de los cuentos de miedo. Madrid: Júcar.

LóPez-PellisA, T. y Ruiz GARzón, R. (2019). "Introducción. Las hijas de Metis". En Insólitas. Narradoras de lo fantástico en Latinoamérica y España, T. LópezPellisa y R. Ruiz Garzón (eds.), XI-XXXI. Madrid: Páginas de Espuma.

LÓPEZ SANTOS, M. (2008). "Teoría de la novela gótica”. Estudios Humanísticos. Filología 30, 187-210. Disponible en línea: http://revpubli.unileon.es/ojs/ index.php/EEHHFilologia/article/view/2840/2017 [03/11/2020].

Moers, E. (1976). Literary Women. The Great Writers. Nueva York: Doubleday \& Co.

NúÑEZ PueNTE, S. (2016). "La construcción de nuevos imaginarios en la obra de Pilar Pedraza: la representación de la figura femenina y los espacios disruptivos". En Images of Women in Hispanic Culture, T. Fernández Ulloa \& J. Schmidt Morazzani (eds.), 155-171. Cambridge: Cambridge Scholars Publishing.

PALMIERI, V. (2017). "Retratos de mujeres salvajes en la ficción de Pilar Pedraza". Confluenze. Rivista di Studi Iberoamericani 9.2, 161-186. Disponible en línea: https://confluenze.unibo.it/article/download/7782/7493 [03/11/2020].

PedrazA, P. (1990). La pequeña pasión. Barcelona: Tusquets. (1996). Paisaje con reptiles. Madrid: Valdemar.

(2008). Vigencia de lo fantástico en el imaginario moderno. Cuenca: Centro de Profesores de Cuenca.

(2009a [2003]). La perra de Alejandría. Madrid: Valdemar. (2009b [1987]). La fase del rubi. Madrid: Valdemar.

(2009c [2000]). “Mater Tenebrarum”. En Felices pesadillas. Los mejores relatos de terror aparecidos en Valdemar (1987-2003), 951-982. Madrid: Valdemar.

(2014). Brujas, sapos y aquelarres. Madrid: Valdemar.

(2015). Lobas de Tesalia. Madrid: Valdemar.

(2018). El amante germano. Madrid: Valdemar.

(2020). Suspiria. Las ministras del mal. Valencia: Asociación Shangrila Textos Aparte.

PÉREZ OCHANDO, L. (2018). "Escrito al margen de la historia. La trilogía de Las antiguas de Pilar Pedraza". Quimera 415-416, 82-84.

PritchetT, K. (2015). Dark Assemblages: Pilar Pedraza and the Gothic Story of Development. Lewisburg: Bucknell University Press. 
Punter, D. (2014 [1996]). The Literature of Terror. A History of Gothic Fictions from 1765 to the Present Day. Volume 1: The Gothic Tradition. London / New York: Routledge.

RAE y ASALE (2014). Diccionario de la Lengua Española (23 a ed.). Disponible en línea: https://dle.rae.es/ [03/11/2020].

RiCHTER, A. (2011). Le fantastique féminin, un art sauvage. Lausana: L'Âge d'Homme.

RoAs, D. (2011). Tras los límites de lo real. Una definición de lo fantástico. Madrid: Páginas de Espuma.

(2019). "El monstruo fantástico posmoderno: entre la anomalía y la domesticación". Revista de Literatura LXXXI.161, 29-56. Disponible en línea: http://revistadeliteratura.revistas.csic.es /index.php/revistadeliteratura/article/view/482 [19/02/2021].

Robles Moreno, L. (2006). "Rubíes y reptiles: la narrativa gótica de Pilar Pedraza". Arbor. Ciencia, Pensamiento y Cultura CLXXXII.720, 563-571. Disponible en línea: http://arbor.revistas.csic.es/index.php/arbor/article/view/52/52 [03/11/2020].

SuÁrez Briones, B. (2002), "Imperatrice o la nueva condesa sangrienta: en torno a $L a$ fase del rubi, de Pilar Pedraza". En Perversas y divinas. La representación de la mujer en las literaturas hispánicas, C. Riera, M. Torras e I. Clúa (eds.), 335-340. Valencia: eXcultura.

VILAR-Bou, J. M. (2016). “'Los jóvenes deben crear sus propios ídolos culturales, y los nuestros deben quedar atrás" [entrevista a Pilar Pedraza]. Eldiario.es, 23 de enero. Disponible en línea: https://www.eldiario.es/murcia/entrevistas/jovenesdeben-propios-idolos-culturales_128_4223894.html [03/11/2020].

Villalba, M. (2002). "Entrevista a Pilar Pedraza". CiberLetras 8. Disponible en línea: http://www.lehman.cuny.edu/ciberletras/v08/villalbaalvarez.html [03/11/2020].

Wallace, D. y Smith, A., EDS. (2009). The Female Gothic. New Directions. London: Palgrave Macmillan.

WiLDBuRG, S. (2015 [2007]). “¿Crees en los hechizos? W.I.T.C.H. o la guerrilla que abrazó el lado oscuro". En W.I.T.C.H. (Conspiración Terrorista Internacional de las Mujeres del Infierno). Comunicados y hechizos, 15-34. Madrid: La Felguera Editores.

Williams, A. (1995). Art of Darkness. A Poetics of Gothic. Chicago: University Press.

This work is licensed under a Creative Commons AttributionNonCommercial-NoDerivatives 4.0 International (CC BY-NC-ND).

Fecha de recepción: 16/11/2020

Fecha de aceptación: 15/03/2021 